\title{
Déclaration de Jürg Lauber
}

\author{
Représentant permanent de la Suisse auprès des Nations Unies
}

\section{(French original)}

J'ai l'honneur, en tant que représentant de l'État hôte des réunions de la Commission du droit international, de prononcer quelques mots pour célébrer cette occasion si spéciale qu'est le soixante-dixième anniversaire de la Commission du droit international.

L'importance de cette journée relève tout d'abord d'un simple constat: le droit international public est un élément central des relations entre les États et constitue la base d'un ordre international stable, juste et pacifique. Pour cette raison, le renforcement du droit international public est un élément fondamental de la Charte des Nations Unies et de la politique étrangère de la Suisse. Si ce constat valait il y a 70 ans déjà, force est de constater qu'il conserve toute sa pertinence de nos jours, particulièrement dans un monde en mutation.

La Commission du droit international a été créée dans le but de promouvoir le développement progressif du droit international et sa codification. Depuis 70 ans, la Commission s'est penchée sur des thèmes très variés tels que les réserves aux traités, les effets des conflits armés sur les traités, la succession d'États et de gouvernements, les immunités juridictionnelles des États et de leurs biens, la responsabilité des États, pour ne citer que quelques exemples. Le traitement de ces thèmes et de bien d'autres sujets d'actualité pour le droit international a permis à la Commission de contribuer activement au développement et à la codification du droit international public. Nous attendons déjà avec grand intérêt le résultat des travaux de la Commission sur les thèmes actuellement à l'agenda comme les normes impératives du droit international, les crimes contre l'humanité, la protection de l'environnement en rapport avec les conflits armés et l'immunité de juridiction pénale étrangère des représentants de l'État.

La Commission choisit des thèmes qui répondent à des critères tels que les besoins des États en matière de codification du droit international, les tendances nouvelles et les préoccupations pressantes des États. En faisant ceci, elle s'assure que le fruit de ses travaux est d'une grande utilité pour la communauté internationale. Ces critères conservent toute leur pertinence de nos jours.

Pour ces raisons, la Suisse est fière d'accueillir les réunions de la Commission du droit international à Genève et de pouvoir, par ce biais, contribuer à son activité. 
Tout en saluant tout effort visant à renforcer le dialogue entre la Sixième Commission de l'Assemblée générale et la Commission du droit international, le choix de Genève comme siège des réunions de la Commission du droit international permet notamment de garantir la complète indépendance de son activité par rapport à la Sixième Commission, qui siège à New York et dont le travail est également hautement apprécié. Nous estimons que la diversité des cultures juridiques propres à ces deux organes constitue un atout pour le développement du droit international. Par ailleurs, une présence à Genève offre des synergies avec plus de 30 organisations internationales actives dans les domaines qui influencent le quotidien de chacun.

Il nous paraît également important de rappeler dans ce contexte, et aussi dans une optique de valorisation de la langue française, qu'il est indispensable que le droit international et son développement soient promus non seulement depuis le siège de New York, mais également depuis celui de Genève. À cet égard, on rappellera le Séminaire du droit international qui se tient chaque année à Genève et permet à ses participants - étudiants, professeurs, fonctionnaires - de se familiariser avec les travaux de la Commission du droit international, notamment en assistant aux séances publiques et aux conférences animées par ses membres.

La Suisse se réjouit de participer aux événements organisés ici à New York et à Genève les 5 et 6 juillet pour célébrer la création si importante de la Commission du droit international il y a 70 ans. 